\title{
Gabapentin Inhibits Protein Kinase C Epsilon Translocation in Cultured Sensory Neurons with Additive Effects When Coapplied with Paracetamol (Acetaminophen)
}

\author{
Vittorio Vellani $^{1}$ and Chiara Giacomoni ${ }^{2}$ \\ ${ }^{1}$ Dipartimento di Scienze Biomediche, Metaboliche e Neuroscienze, Università di Modena e Reggio Emilia, \\ Via Campi 287, 41125 Modena, Italy \\ ${ }^{2}$ Dipartimento di Economia, Scienze e Diritto, Università degli Studi della Repubblica di San Marino, Salita alla Rocca 44, \\ 47890 San Marino (Città), San Marino \\ Correspondence should be addressed to Vittorio Vellani; vvellani@unimore.it
}

Received 9 November 2016; Accepted 17 January 2017; Published 16 February 2017

Academic Editor: Valdir Cechinel Filho

Copyright (C) 2017 Vittorio Vellani and Chiara Giacomoni. This is an open access article distributed under the Creative Commons Attribution License, which permits unrestricted use, distribution, and reproduction in any medium, provided the original work is properly cited.

\begin{abstract}
Gabapentin is a well-established anticonvulsant drug which is also effective for the treatment of neuropathic pain. Although the exact mechanism leading to relief of allodynia and hyperalgesia caused by neuropathy is not known, the blocking effect of gabapentin on voltage-dependent calcium channels has been proposed to be involved. In order to further evaluate its analgesic mechanisms, we tested the efficacy of gabapentin on protein kinase $\mathrm{C}$ epsilon (PKCe ) translocation in cultured peripheral neurons isolated from rat dorsal root ganglia (DRGs). We found that gabapentin significantly reduced PKCe translocation induced by the pronociceptive peptides bradykinin and prokineticin 2, involved in both inflammatory and chronic pain. We recently showed that paracetamol (acetaminophen), a very commonly used analgesic drug, also produces inhibition of PKC $\varepsilon$. We tested the effect of the combined use of paracetamol and gabapentin, and we found that the inhibition of translocation adds up. Our study provides a novel mechanism of action for gabapentin in sensory neurons and suggests a mechanism of action for the combined use of paracetamol and gabapentin, which has recently been shown to be effective, with a cumulative behavior, in the control of postoperative pain in human patients.
\end{abstract}

\section{Introduction}

Gabapentin, a structural analogue of the inhibitory neurotransmitter gamma-aminobutyric acid, was originally developed in the early nineties as a third-generation antiepileptic drug. Besides epilepsy, gabapentin has been reported to be effective for the treatment of other pathological states such psychiatric and movement disorders, alcohol addiction, and restless leg syndrome [1]. In particular, gabapentin has been shown to have central and peripheral antinociceptive activity in several painful states with neuropathic-related features [2], including the inflammatory hyperalgesia and allodynia which develop after surgical procedures and may induce central sensitization and eventually neuropathic pain [3].
Paracetamol is a nonprescription analgesic/antipyretic drug with little anti-inflammatory activity and partial inhibition of COX-1 and COX-2 [4,5], of widespread use both as a self-administered medication and in the clinical practice. The combination of gabapentin and paracetamol has been successfully used in postoperative patients, showing additive effect on morphine sparing [6]. Little is known about how gabapentin and paracetamol combine their actions to produce analgesia, but the additive effect suggests that convergence on related mechanisms may be hypothesized.

The epsilon isoform of protein kinase C (PKCE) is a very important noxious effector $[7,8]$ currently regarded as a novel target for therapeutic intervention. PKC $\varepsilon$ is involved in both inflammatory and neuropathic pain states 
[9-12] caused by diabetes [13] and alcohol abuse [14] and during chemotherapy [15]. Translocation is necessary to allow phosporylation by PKCE of specific cellular targets located in the plasma membrane in nociceptive neurons $[16,17]$, including TRPV1 (Transient Receptor Potential Vanilloid 1) ion channels [18] and several other targets involved in nociceptor sensitization and excitability. Inhibition of translocation in peripheral fibers will prevent phosphorylation activity and result in antinociceptive effects in sensory neurons. Indeed, local, intradermal injection of PKCe specific inhibitors at the site of nociceptive testing significantly inhibited pain in several models of peripheral hyperalgesia [13-15]. We recently showed that nimesulide, a nonsteroidal anti-inflammatory drug (NSAID), and paracetamol inhibit translocation of PKC $\varepsilon$ induced in cultured sensory neurons by bradykinin and thrombin, inflammatory mediators that sensitize TRPV1 to heat stimuli and to capsaicin [18-21]. We therefore proposed that nimesulide and paracetamol may exert a significant part of their analgesic effects with a mechanism of action based on PKCe inhibition of translocation in DRG neurons.

In this paper, to elicit translocation, as well as bradykinin $[12,22]$, we use the peptide prokineticin 2 (PK2), involved in both inflammatory [23-25] and neuropathic [25] states, which activate $\mathrm{PKC} \varepsilon$ via Gq-coupled receptors in nociceptive neurons $[16,23]$. We show with a well-established immunocytochemistry technique that gabapentin significantly and dose-dependently inhibits $\mathrm{PKC} \varepsilon$ translocation induced by bradykinin and PK2, with an effect that adds up to the effect of paracetamol.

\section{Materials and Methods}

2.1. Dorsal Root Ganglion Primary Cultures. Sprague-Dawley rats (2-6 weeks old) were sacrificed under total anaesthesia according to Italian and European legislation, with protocols in agreement with the guidelines of the Committee for Research and Ethical Issues of IASP published in PAIN ${ }^{\circledR}$, 16 (1983) pp. 109-110. Experimental protocols were also approved by local institutional animal care and use committee. Dorsal root ganglia (DRGs) were collected, incubated for $1 \mathrm{~h}$ at $37^{\circ} \mathrm{C}$ with $0.125 \%$ collagenase (Sigma-Aldrich, Milan, IT), mechanically dissociated, and then plated onto glass coverslips precoated with $10 \mu \mathrm{g} / \mathrm{mL}$ poly-L-lysine and $10 \mu \mathrm{g} / \mathrm{mL}$ laminin (Sigma). Cells were cultured in DMEM in the presence of $1.5 \mu \mathrm{g} / \mathrm{mL}$ cytosine 1-D-arabinofuranoside (ARA-C, from Sigma), 10\% fetal bovine serum, 1\% penicillin/streptomycin, and 1\% L-glutamine (Invitrogen, San Diego, CA), and $100 \mathrm{ng} / \mathrm{mL}$ NGF (7s, Sigma) was also added as described previously, in order to improve neuronal survival and bradykinin and $\mathrm{PK} 2$ receptor expression, as it is common practice with this preparation $[23,26,27]$.

2.2. Immunocytochemistry. Translocation of PKCe from the cytoplasm to the plasma membrane was visualized as previously described [12, 19, 23]. In brief, rat DRG neurons cultured for 2 days were rapidly exposed to bradykinin at $1 \mu \mathrm{M}$ concentration or to $\mathrm{PK} 2(100 \mathrm{nM})$ for $30 \mathrm{~s}$ and fixed for $10 \mathrm{~min}$ at room temperature with paraformaldehyde (4\% formaldehyde and $4 \%$ sucrose, in PBS/distilled water $2: 1)$. Cells were pretreated for different times and different concentrations of gabapentin (see Results) alone or in combination with paracetamol at different concentrations (see Results). Water was used to prepare stock solutions for gabapentin, while DMSO was used for paracetamol. Final concentration of DMSO applied to cells was $1: 1000$, equal in all experiments. The stimulation with PK2 or bradykinin contained the same concentrations of drugs preapplied. Fixed cells were washed three times in PBS (with $0.1 \%$ fish skin gelatin to block nonspecific sites), permeabilized for $30 \mathrm{~min}$ at room temperature with Triton X-100 (0.2\% in PBS with no divalent ions added), and incubated overnight at $4^{\circ} \mathrm{C}$ with a polyclonal anti-PKCe antibody [16] diluted $1: 1000$ in PBST/gelatin (PBS with $0.05 \%$ Triton X-100). Coverslips were rinsed several times with PBS and then stained overnight with donkey anti-rabbit IgG conjugated to the fluorophore Alexa Fluor 488 (1:1000, Thermo Scientific, Waltham, MA, USA). Finally, the secondary antibody was rinsed off with PBS and cells were analyzed using a confocal microscope (Leica SP2, Leica Microsystems, Milan, Italy). Activation of PKC $\varepsilon$ following activation of bradykinin or prokineticin receptors (PKRs) resulted in translocation from the cytoplasm to the neuronal cell membrane, as shown several times before $[19,20]$. Translocation was quantified by determining fluorescence intensity along a line positioned across the cell in order to avoid the nucleus (for details, see Cesare et al. [21]) using semiautomated proprietary software which significantly improved efficiency of data analysis. Neurons in which intensity at the cell membrane was at least $2.0 \mathrm{x}$ greater than the mean of cytoplasmic intensity were counted as positive. In order to improve data reproducibility and signal/noise ratio, a very large number of cells were counted: $>1000$ cells per coverslip, at least 3-4 coverslips per culture, 3-12 cultures per data point. All experiments were analyzed in blind conditions.

2.3. Statistical Analysis. Data were analyzed by one-way analysis of variance (ANOVA), followed by Bonferroni's $t$ test for multiple comparison. An effect was determined to be significant if the $P$ value was below 0.05 .

\section{Results}

$\mathrm{PKC} \varepsilon$ activation was quantified in an all-or-nothing fashion as the number of neurons in which translocation is observed (see Figure 1), in a very large number of neurons per each experiment, in order to enhance the resolution of this technique (see Methods). Using this experimental approach, it is possible to quantitate the effect of drugs interfering with translocation and to obtain dose-response and time-course curves [23]. Following application of $1 \mu \mathrm{M}$ bradykinin or $100 \mathrm{nM}$ prokineticin 2, which are saturating concentrations for these agonists, maximum translocation was consistently observed. Longer application times were avoided as they would cause PKC $\varepsilon$ to be internalized, as shown and discussed previously $[16,19,20,23,28]$. In this set of experiments, 


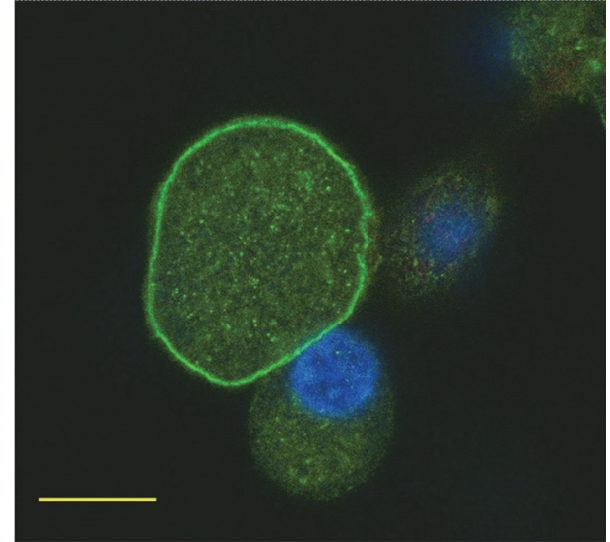

FIgURE 1: Confocal optical sections of cultured sensory neurons treated with prokineticin $2(100 \mathrm{nM})$ for 30 seconds and subsequently fixed and stained for PKCe with a polyclonal specific antibody. Nuclei were stained in blue with DAPI. The largest neuron is showing translocation of $\mathrm{PKC} \varepsilon$ to the plasma membrane; the smaller neurons represent a typical example of nontranslocated neurons. Translocation induced by $1 \mu \mathrm{M}$ bradykinin (BK) for 30 seconds had identical appearance. Scale bar: $5 \mu \mathrm{m}$.

bradykinin at $30 \mathrm{~s}$ produced translocation in $32.0 \pm 0.6 \%$ and PK2 in $23.6 \pm 0.5 \%$ of DRG neurons, consistently with previous work $[12,16,19,20,26]$.

As shown in Figure 2(a), the percentage of neurons in which bradykinin receptor activation caused translocation was dose-dependently decreased by $5 \mathrm{~min}$ preapplication of gabapentin in the range $10 \mathrm{nM}-500 \mu \mathrm{M}$ to a value of $26.8 \pm 0.7 \%$ for the largest concentration tested. Inhibition therefore was about $17.8 \%$. Similarly, the control value of translocation for PK2 experiments decreased to $17.6 \pm 0.5$ for the concentration of $200 \mu \mathrm{M}$ gabapentin, with overall inhibition of about $34 \%$.

Dose-response curves were well fitted with the Hill equation with the following parameters: for bradykinin-induced translocation, gabapentin $\mathrm{ED}_{50}=3.8 \pm 0.7 \mu \mathrm{M}$ and Hill slope $=0.5 \pm 0.1$; for $\mathrm{PK} 2$-induced translocation, $\mathrm{ED}_{50}=1.9 \pm 0.3 \mu \mathrm{M}$ and Hill slope $=0.7 \pm 0.1$.

Dose responses were obtained after $5 \mathrm{~min}$ pretreatment with gabapentin, applied in culture medium and present also in the bradykinin or PK2 stimulation solution. In Figure 2(b), we show that longer treatments $(30 \mathrm{~min}, 2$ hours, and 24 hours) produced no significant time-dependent change in the fractional effect of gabapentin at $200 \mu \mathrm{M}$ concentration.

As described in Figure 3(a), paracetamol $(10 \mu \mathrm{M})$, as previously observed [19, 20], inhibited translocation by bradykinin. In this new set of experiments, translocation was reduced from the control value of $32.3 \pm 0.9$ to $21.5 \pm 0.4 \%$. A similar result was obtained with $\mathrm{PK} 2$-induced translocation from $23.6 \pm 0.2 \%$ to $19.0 \pm 0.5 \%$. All experiments were repeated in 5 different cultures.

Combined application of gabapentin and paracetamol resulted in summation of the respective effects, with a reduction from the control value to $16.2 \pm 0.3 \%$ and to $13.2 \pm$ $0.4 \%$, respectively, in experiments with bradykinin and with PK2.
In order to further investigate the nature of the apparently additive behavior of gabapentin and paracetamol effect, we performed a full isobolographic analysis, which confirmed an additive behavior, with no sign of synergistic interaction (Figure 3(b)).

\section{Discussion}

Gabapentin, paracetamol, nonsteroid anti-inflammatory drugs (NSAIDs), selective COX-2 inhibitors, and glucocorticoids are nonopioid drugs which display clinically relevant analgesic properties. In postoperative pain management, patients are very often treated with combinations of the above nonopioid analgesics to reduce opioid-related adverse effects. Although a variety of combinations have recently been tested and although some of them are currently employed in clinical practice [29], the rationale and the molecular mechanisms behind the combined use of nonopioid analgesic drugs are often not quite well documented. Recently, it was shown that gabapentin in combination with other drugs with minimal adverse effects such as paracetamol [30] allowed significant opioid sparing with positive effects in postsurgical patients. So far, gabapentin was believed to produce its antinociceptive effects mainly by actions on voltage-gated ion channels, neurotransmitter ionotropic receptors, and L-amino acid transporters [31]. Such actions are therefore supposed to occur centrally, where most of such sites of action are located. Indeed, gabapentin actions both in spinal and in supraspinal sites have been described [32]. Previously, some involvement of PKC in antinociceptive effects of gabapentin was reported in the trigeminal nucleus [33] and in spinal cord dorsal horn [34]. In a very recent report [35], this result was confirmed, with indirect evidence of the involvement of dorsal horn $\varepsilon$ and $\gamma$ PKC isoforms in a visceral pain model [36]. The western blot technique employed in those studies does not allow discrimination of the cell localization where PKCe inhibition of translocation occurs, but a contribution of presynaptic PKC $\varepsilon$, present in the central terminal of the sensory neuron, consistent with the one we report here, is largely possible. The $\gamma$ isoform of PKC $(\mathrm{PKC} \gamma)$ is not expressed in dorsal root ganglia [16]; therefore, activation of PKC $\gamma$ can only occur downstream of the sensory neuron, or in surrounding nonneuronal cells. In this context, our paper contributes the first demonstration of PKC-involving antinociceptive functions of gabapentin in the therapeutic range of concentrations in the peripheral nervous system, by providing the first direct evidence that a dose-dependent, significant effect is produced by gabapentin with a mechanism that involves specific inhibition of translocation of the $\varepsilon$ PKC isoform in sensory neurons. This mechanism is likely a relevant part of gabapentin antinociceptive action, as the lack of translocation will prevent sensitization of membrane targets in the significant percentage of sensory neurons where complete inhibition occurs.

The present study shows also that the effect of gabapentin combined with paracetamol, in comparison to each drug alone, adds to the effect of each other. This observation is consistent with a previous study on acute postoperative 

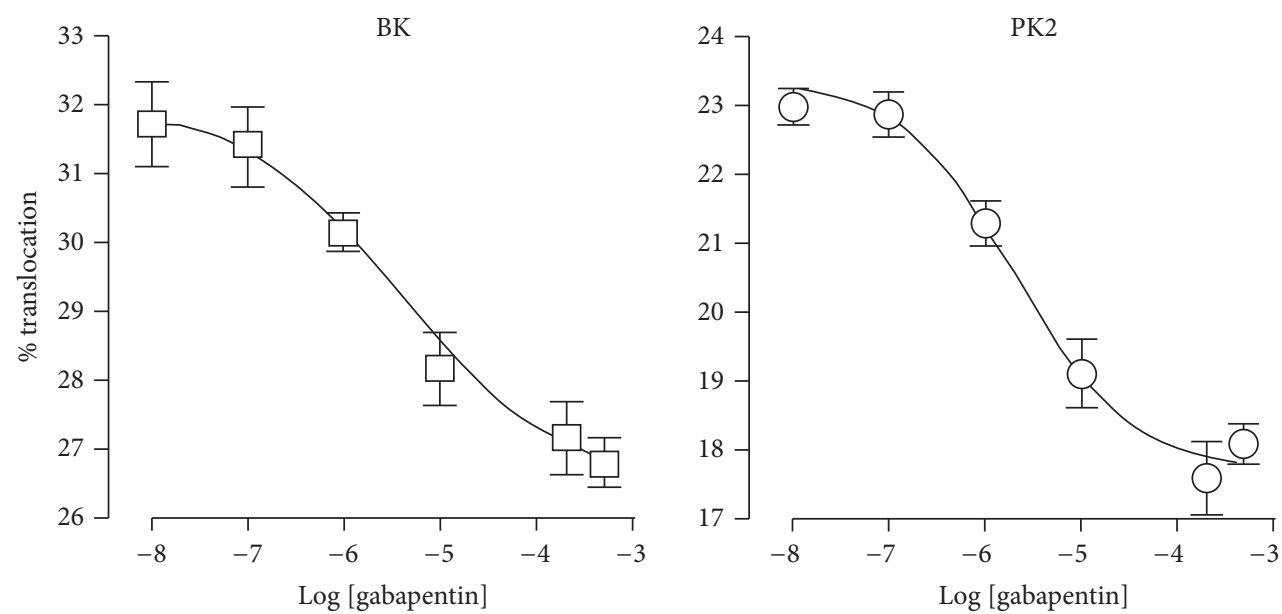

(a)
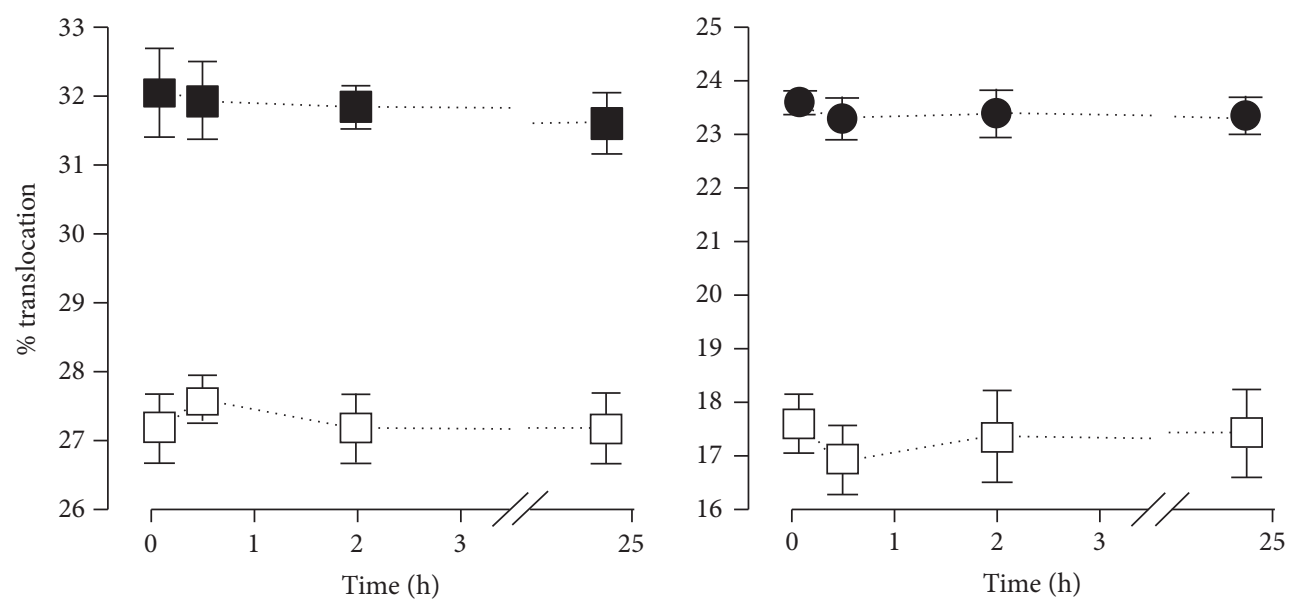

(b)

FIGURE 2: PKC translocation induced by bradykinin and PK2 is dose-dependently inhibited by gabapentin. (a) Gabapentin dose-response data on bradykinin-induced (white square symbols) and PK2-induced translocation (white circles). Gabapentin was preapplied for 5 minutes, and then neurons were treated with $1 \mu \mathrm{M}$ bradykinin or $100 \mathrm{nM}$ PK2 for $30 \mathrm{~s}$ in the presence of the same preapplied concentration. (b) Time course of translocation at different times in control culture medium (black symbols) and in the same medium with $200 \mu \mathrm{M}$ gabapentin added (white symbols). Both bradykinin- and PK2-induced translocation and gabapentin effect are not time-dependent in these conditions. See Results for further details. Notes: values are means \pm SEM of data from 4-7 separate cultures.

pain, demonstrating that the combination of gabapentin and paracetamol reduced morphine self-administration in a randomized and double-blinded manner in human patients suffering from postoperative pain [6]. Although in that study it is not possible to discriminate between peripheral and central effects of these drugs, our study suggests that the peripheral effect is likely to contribute significantly to the overall analgesia. In this context, the observed inhibition of PKCE translocation by gabapentin and by paracetamol appears to be highly relevant for a proper understanding of the multifactorial pharmacological actions of these drugs. Inhibitory effects by gabapentin and paracetamol were largely similar both in bradykinin- and in PK2-induced translocation, suggesting that these drugs do not specifically interact with bradykinin and PK2 membrane receptors but rather affect mechanisms of translocation intracellular pathway, possibly directly on $\mathrm{PKC} \varepsilon$ itself, or on the interaction of PKC $\varepsilon$ with the receptors for the specific activated protein kinase $C$ isoform, RACKs [37]. The fact that gabapentin and paracetamol effects on PKC $\varepsilon$ are additive suggests that the overall inhibition of translocation is likely obtained with one or perhaps two different molecular mechanisms activated by each drug, converging on the same downstream action on $\mathrm{PKC} \varepsilon$, which are present in specific subsets of neurons. Sensory neurons are well known to represent a highly heterogeneous population, with different morphological, neurochemical, and biochemical properties [38]. The observation that the gabapentin-induced reduction of fractional suppression of translocated neurons is about double for PK2-stimulated in comparison to bradykininstimulated neurons (see Results) is consistent with the difference in populations expressing the PK2 receptor, the latter almost exclusively isolectin B4-negative [23] and the 

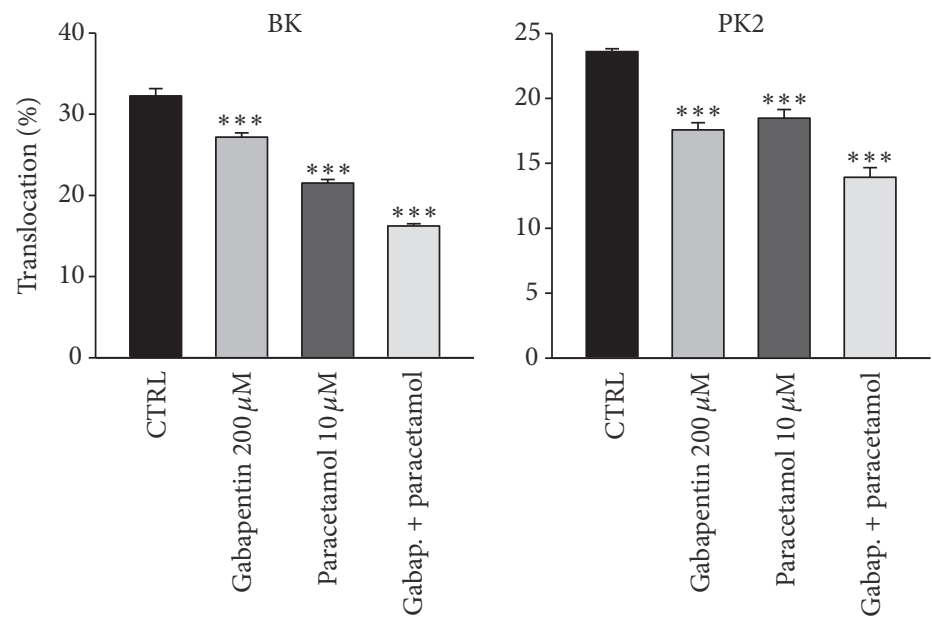

(a)
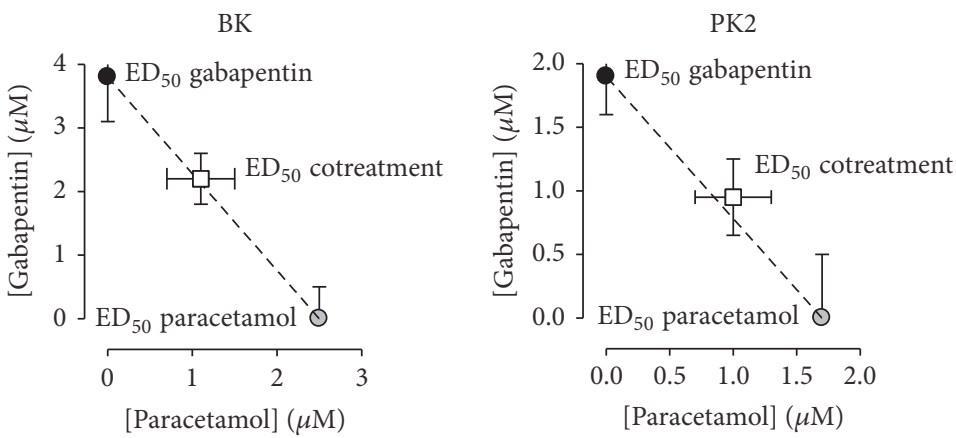

(b)

FIGURE 3: PKC translocation suppression by gabapentin and by paracetamol is additive. (a) Experiments on bradykinin- (BK-) induced and PK2-induced PKCe translocation. Gabapentin effect on the latter was almost double compared to the former, with about $14.2 \%$ suppression on bradykinin-induced translocation and $25.4 \%$ suppression on PK2-induced translocation, compared to control (CTRL). Paracetamol-induced suppression was $33.4 \%$ (BK) and $21.6 \%$ (PK2). Combined drug suppression was, respectively, $49.8 \%$ and $41.9 \%$, consistent with an additive effect of these drugs. (b) Isobolograms for the effects of gabapentin and paracetamol, alone or in combination, in BK- and PK2-induced $\mathrm{PKC} \varepsilon$ translocation. White square symbols correspond to the experimental cotreatment $\mathrm{ED}_{50}$ with $95 \%$ confidence limits. Circle symbols correspond to $\mathrm{ED}_{50}$ for gabapentin and paracetamol alone. Notes: values are means \pm SEM of data from 5 separate cultures. ${ }^{* * *} P<0.001$ versus control and versus other treatments in all combinations (ANOVA followed by Bonferroni's $t$-test).

former both isolectin B4-positive and isolectin B4-negative (unpublished observation, consistent with the literature [12, $39,40])$ only partially overlapping [23].

More work is necessary to determine the nature of mechanisms preventing translocation in these specific subsets of neurons. Further experiments that will determine whether other novel or classic antinociceptive drugs currently in use, as well as paracetamol and gabapentin, produce part of their effect via inhibition of PKCE translocation and whether their combined effects are additive or possibly synergistic are currently in progress in our labs.

\section{Conclusion}

In conclusion, our results help to clarify the pharmacological action of largely used drugs such as gabapentin and paracetamol and of their combined use. From these results, in combination with data in the literature, gabapentin emerges as a drug with multifactorial modes of action on the pain pathway, with an increasing number of novel, interesting mechanisms not only in the central but also in the peripheral nervous system.

\section{Competing Interests}

The authors report no competing interests in this work.

\section{Acknowledgments}

This work was supported by grants from Fondazione Cassa di Risparmio di Modena and Fondazione Cassa di Risparmio di Carpi. The authors thank Matteo Corradini and Giuseppina Leo for excellent technical assistance. The programmable fast solution changer used for immunocytochemistry experiments was a gift from CV Scientific (http://www .cvscientific.com). 


\section{References}

[1] L. Magnus, "Nonepileptic uses of gabapentin," Epilepsia, vol. 40, no. 6, pp. S66-S72, 1999.

[2] R. A. Moore, P. J. Wiffen, S. Derry, T. Toelle, and A. S. Rice, "Gabapentin for chronic neuropathic pain and fibromyalgia in adults," Cochrane Database of Systematic Reviews, no. 4, Article ID CD007938, 2014.

[3] O. Mathiesen, S. Møiniche, and J. B. Dahl, "Gabapentin and postoperative pain: a qualitative and quantitative systematic review, with focus on procedure," BMC Anesthesiology, vol. 7, article 6, pp. 1-15, 2007.

[4] P. J. Harvison, R. W. Egan, P. H. Gale, and S. D. Nelson, "Acetaminophen as a cosubstrate and inhibitor of prostaglandin H synthase," Advances in experimental medicine and biology, vol. 197, pp. 739-747, 1986.

[5] S. Ohki, N. Ogino, S. Yamamoto, and O. Hayaishi, "Prostaglandin hydroperoxidase, an integral part of prostaglandin endoperoxide synthetase from bovine vesicular gland microsomes," The Journal of Biological Chemistry, vol. 254, no. 3, pp. 829-836, 1979.

[6] M. Durmus, A. K. But, V. Saricicek, H. I. Toprak, and M. O. Ersoy, "The post-operative analgesic effects of a combination of gabapentin and paracetamol in patients undergoing abdominal hysterectomy: a randomized clinical trial," Acta Anaesthesiologica Scandinavica, vol. 51, no. 3, pp. 299-304, 2007.

[7] M. C. Souroujon and D. Mochly-Rosen, "Peptide modulators of protein-protein interactions in intracellular signaling," Nature Biotechnology, vol. 16, no. 10, pp. 919-924, 1998.

[8] R. Brandman, M.-H. Disatnik, E. Churchill, and D. MochlyRosen, "Peptides derived from the $\mathrm{C} 2$ domain of protein kinase $\mathrm{C} \varepsilon(\varepsilon \mathrm{PKC})$ modulate $\varepsilon \mathrm{PKC}$ activity and identify potential protein-protein interaction surfaces," Journal of Biological Chemistry, vol. 282, no. 6, pp. 4113-4123, 2007.

[9] J. Huang, X. Zhang, and P. A. McNaughton, "Modulation of temperature-sensitive TRP channels," Seminars in Cell and Developmental Biology, vol. 17, no. 6, pp. 638-645, 2006.

[10] K. O. Aley, R. O. Messing, D. Mochly-Rosen, and J. D. Levine, "Chronic hypersensitivity for inflammatory nociceptor sensitization mediated by the $\varepsilon$ isozyme of protein kinase C," Journal of Neuroscience, vol. 20, no. 12, pp. 4680-4685, 2000.

[11] D. B. Reichling and J. D. Levine, "Critical role of nociceptor plasticity in chronic pain," Trends in Neurosciences, vol. 32, no. 12, pp. 611-618, 2009.

[12] V. Vellani, O. Zachrisson, and P. A. McNaughton, "Functional bradykinin $\mathrm{B} 1$ receptors are expressed in nociceptive neurones and are upregulated by the neurotrophin GDNF," Journal of Physiology, vol. 560, no. 2, pp. 391-401, 2004.

[13] E. K. Joseph and J. D. Levine, "Sexual dimorphism for protein kinase $\mathrm{C} \varepsilon$ signaling in a rat model of vincristine-induced painful peripheral neuropathy," Neuroscience, vol. 119, no. 3, pp. 831-838, 2003.

[14] O. A. Dina, J. Barletta, X. Chen et al., "Key role for the epsilon isoform of protein kinase $\mathrm{C}$ in painful alcoholic neuropathy in the rat," Journal of Neuroscience, vol. 20, no. 22, pp. 8614-8619, 2000.

[15] O. A. Dina, X. Chen, D. Reichling, and J. D. Levine, "Role of protein kinase $\mathrm{C} \varepsilon$ and protein kinase $\mathrm{A}$ in a model of paclitaxelinduced painful peripheral neuropathy in the rat," Neuroscience, vol. 108, no. 3, pp. 507-515, 2001.

[16] P. Cesare, L. V. Dekker, A. Sardini, P. J. Parker, and P. A. McNaughton, "Specific involvement of PKC- $\varepsilon$ in sensitization of the neuronal response to painful heat," Neuron, vol. 23, no. 3 , pp. 617-624, 1999.

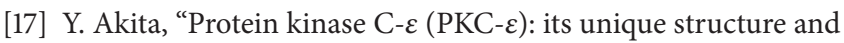
function," Journal of Biochemistry, vol. 132, no. 6, pp. 847-852, 2002.

[18] V. Vellani, S. Mapplebeck, A. Moriondo, J. B. Davis, and P. A. McNaughton, "Protein kinase $\mathrm{C}$ activation potentiates gating of the vanilloid receptor VR1 by capsaicin, protons, heat and anandamide," Journal of Physiology, vol. 534, no. 3, pp. 813-825, 2001.

[19] V. Vellani, S. Franchi, M. Prandini et al., "Nimesulide inhibits protein kinase $\mathrm{C}$ epsilon and substance $\mathrm{P}$ in sensory neuronscomparison with paracetamol," Journal of Pain Research, vol. 4, pp. 177-187, 2011.

[20] V. Vellani, S. Franchi, M. Prandini et al., "Effects of NSAIDs and paracetamol (acetaminophen) on protein kinase $\mathrm{C}$ epsilon translocation and on substance $\mathrm{P}$ synthesis and release in cultured sensory neurons," Journal of Pain Research, vol. 6, pp. 111-120, 2013.

[21] P. Cesare, A. Moriondo, V. Vellani, and P. A. Mcnaughton, "Ion channels gated by heat," Proceedings of the National Academy of Sciences of the United States of America, vol. 96, no. 14, pp. 76587663, 1999.

[22] G. Pethö and P. W. Reeh, "Sensory and signaling mechanisms of bradykinin, eicosanoids, platelet-activating factor, and nitric oxide in peripheral nociceptors," Physiological Reviews, vol. 92, no. 4, pp. 1699-1775, 2012.

[23] V. Vellani, M. Colucci, R. Lattanzi et al., "Sensitization of transient receptor potential vanilloid 1 by the prokineticin receptor agonist Bv8," The Journal of Neuroscience, vol. 26, no. 19, pp. 5109-5116, 2006.

[24] L. Negri, R. Lattanzi, E. Giannini et al., "Impaired nociception and inflammatory pain sensation in mice lacking the prokineticin receptor PKR1: focus on interaction between PKR1 and the capsaicin receptor TRPV1 in pain behavior," Journal of Neuroscience, vol. 26, no. 25, pp. 6716-6727, 2006.

[25] R. Lattanzi, D. Maftei, V. Marconi et al., "Prokineticin 2 upregulation in the peripheral nervous system has a major role in triggering and maintaining neuropathic pain in the chronic constriction injury model," BioMed Research International, vol. 2015, Article ID 301292, 15 pages, 2015.

[26] V. Vellani, M. Prandini, C. Giacomoni, G. Pavesi, L. Ravegnani, and P. C. Magherini, "Functional endothelin receptors are selectively expressed in isolectin B4-negative sensory neurons and are upregulated in isolectin B4-positive neurons by neurturin and glia-derived neurotropic factor," Brain Research, vol. 1381, pp. 31-37, 2011.

[27] Y.-J. Lee, O. Zachrisson, D. A. Tonge, and P. A. McNaughton, "Upregulation of bradykinin B2 receptor expression by neurotrophic factors and nerve injury in mouse sensory neurons," Molecular and Cellular Neuroscience, vol. 19, no. 2, pp. 186-200, 2002.

[28] V. Vellani, A. M. Kinsey, M. Prandini et al., "Protease activated receptors 1 and 4 sensitize TRPV1 in nociceptive neurones," Molecular Pain, vol. 6, article no. 61, 2010.

[29] J. B. Dahl, R. V. Nielsen, J. Wetterslev et al., "Post-operative analgesic effects of paracetamol, NSAIDs, glucocorticoids, gabapentinoids and their combinations: a topical review," Acta Anaesthesiologica Scandinavica, vol. 58, no. 10, pp. 1165-1181, 2014.

[30] O. Mathiesen, J. Wetterslev, V. K. Kontinen et al., "Adverse effects of perioperative paracetamol, NSAIDs, glucocorticoids, 
gabapentinoids and their combinations: a topical review," Acta Anaesthesiologica Scandinavica, vol. 58, no. 10, pp. 1182-1198, 2014.

[31] J.-K. Cheng and L.-C. Chiou, "Mechanisms of the antinociceptive action of gabapentin," Journal of Pharmacological Sciences, vol. 100, no. 5, pp. 471-486, 2006.

[32] G. Sills, "The mechanisms of action of gabapentin and pregabalin," Current Opinion in Pharmacology, vol. 6, no. 1, pp. 108113, 2006.

[33] Y. P. Maneuf and A. T. McKnight, "Block by gabapentin of the facilitation of glutamate release from rat trigeminal nucleus following activation of protein kinase C or adenylyl cyclase," British Journal of Pharmacology, vol. 134, no. 2, pp. 237-240, 2001.

[34] Y. Gu and L.-Y. M. Huang, "Gabapentin actions on N-methylD-aspartate receptor channels are protein kinase C-dependent," Pain, vol. 93, no. 1, pp. 85-92, 2001.

[35] Y.-B. Zhang, Z.-D. Guo, M.-Y. Li et al., "Gabapentin effects on PKC-ERK1/2 signaling in the spinal cord of rats with formalininduced visceral inflammatory pain," PLoS ONE, vol. 10, no. 10, Article ID e0141142, 2015.

[36] Y. Zhang, K. Gong, W. Zhou et al., "Involvement of subtypes $\gamma$ and $\varepsilon$ of protein kinase $C$ in colon pain induced by formalin injection," NeuroSignals, vol. 19, no. 3, pp. 142-150, 2011.

[37] D. Mochly-Rosen and A. S. Gordon, "Anchoring proteins for protein kinase C: a means for isozyme selectivity," FASEB Journal, vol. 12, no. 1, pp. 35-42, 1998.

[38] X. Dong, S.-K. Han, M. J. Zylka, M. I. Simon, and D. J. Anderson, "A diverse family of GPCRs expressed in specific subsets of nociceptive sensory neurons," Cell, vol. 106, no. 5, pp. 619-632, 2001.

[39] M. Bandell, G. M. Story, S. W. Hwang et al., "Noxious cold ion channel TRPA1 is activated by pungent compounds and bradykinin," Neuron, vol. 41, no. 6, pp. 849-857, 2004.

[40] M. E. Barabas, E. A. Kossyreva, and C. L. Stucky, “TRPA1 is functionally expressed primarily by IB4-binding, nonpeptidergic mouse and rat sensory neurons," PLOS ONE, vol. 7, no. 10, Article ID e47988, 2012. 

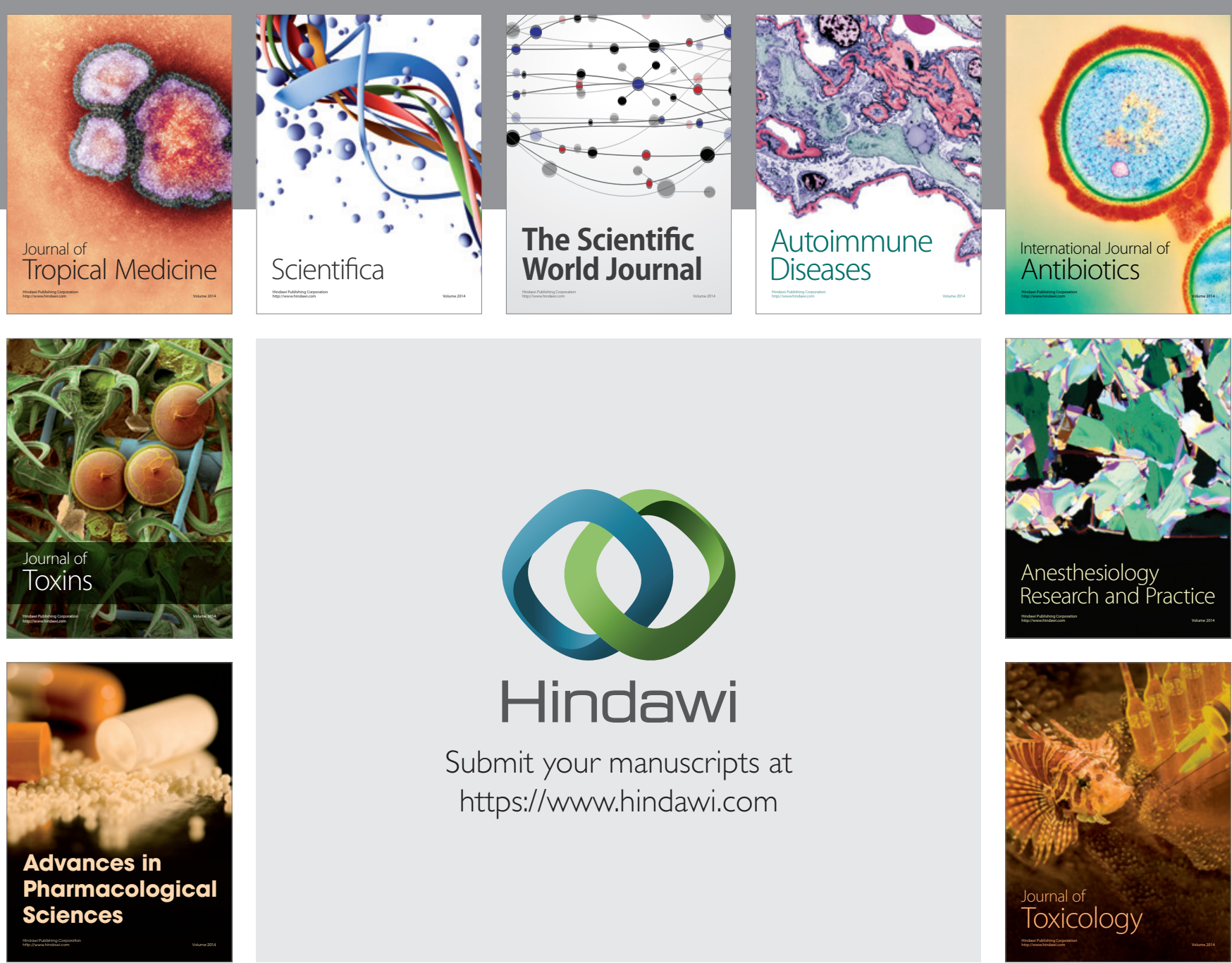

\section{Hindawi}

Submit your manuscripts at

https://www.hindawi.com
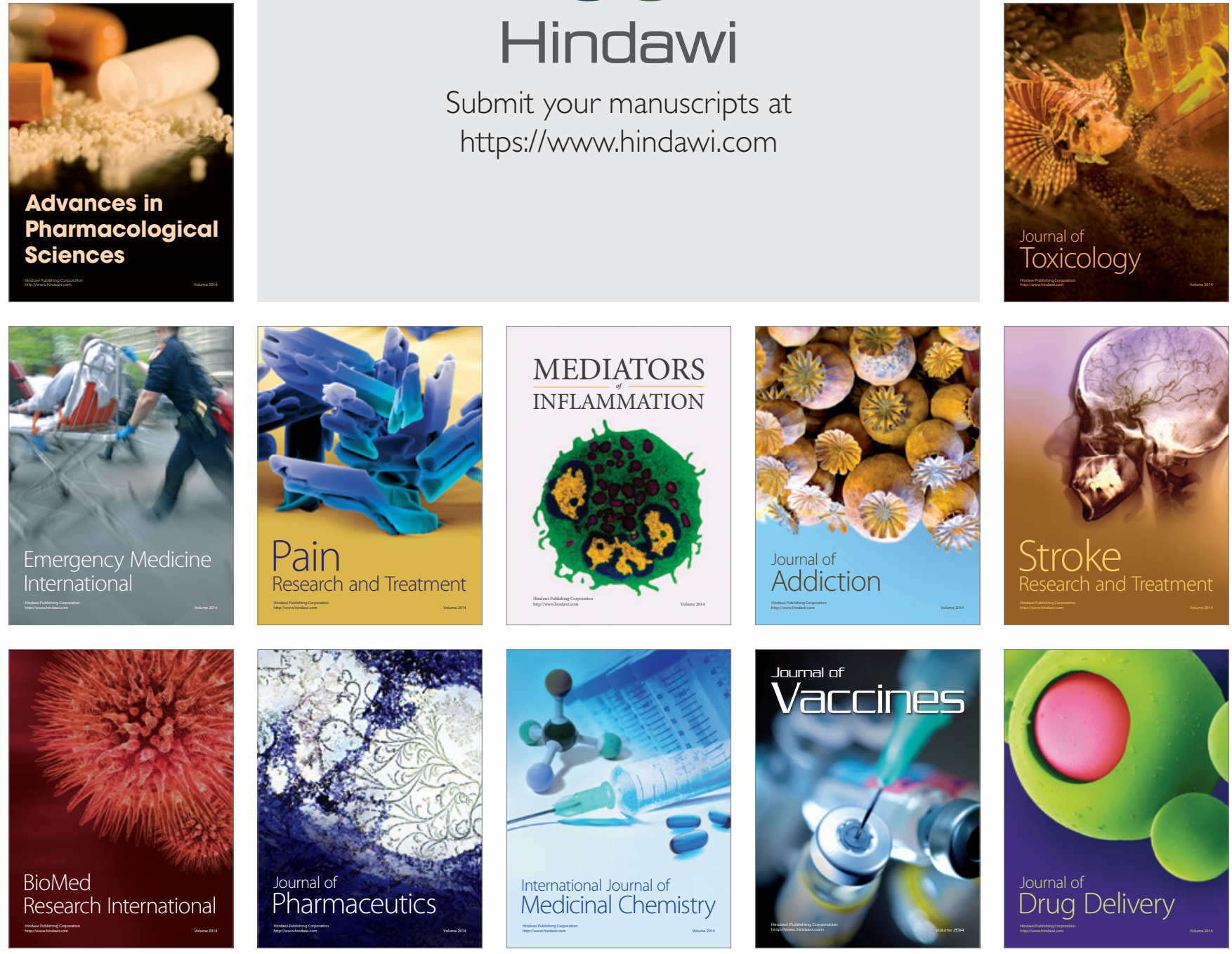